\title{
Videoaulas acessíveis sobre a temática água como recurso didático-pedagógico para promoção da educação científica
}

\author{
Roberto Irineu da Silva ${ }^{1}$ \\ Luciana da Silva Goudinho ${ }^{2}$ \\ Agne de Albuquerque França Ribeiro ${ }^{1}$ \\ Jaderson Pires dos Santos Vasconcelos ${ }^{2}$ (D) \\ Sérgio Crespo Coelho da Silva Pinto ${ }^{2}$ (D) \\ Ruth Maria Mariani Braz ${ }^{2}$ \\ ${ }^{1}$ Colégio Pedro II, Brasil; ${ }^{2}$ Universidade Federal Fluminense (UFF), Brasil
}

Resumo. As escolas são desafiadas a promover uma gestão didático-pedagógica que promova a inclusão de estudantes com deficiência, garantindo acesso equânime aos conteúdos curriculares. Este trabalho desenvolveu uma metodologia de produção de videoaulas acessíveis sobre a temática água, utilizando experimentações como subsídio didático para contextualização dos discentes com processo de produção de conhecimento científico. Os experimentos cognatos ao assunto foram selecionados e realizados com os discentes para verificação das principais dúvidas quanto ao conhecimento científico associado e a manipulações dos materiais. Gerou-se um repositório de videogravações com tradução em língua de sinais. Estas videoaulas $n=5$, totalizando 83 minutos de gravação) foram submetidas à avaliação em relação à qualidade didática e acessibilidade, por profissionais especializados no ensino com surdos e professores de ciências. Considerando o aspecto de publicitação, foram implementados nestes vídeos, um código digital que, uma vez acionado, gera um questionário para verificação da aprendizagem, além do roteiro para replicação dos experimentos. Conclui-se que este artigo pode corroborar para promoção da Educação Científica Inclusiva, considerando sua metodologia de produção centrada nos estudantes como protagonistas, além das videoaulas constituírem-se em recursos de consultas a estudantes, docentes e intérpretes, cumprindo também um papel de formação continuada. Palavras-chave: ensino inclusivo de biologia; acessibilidade; educação de surdos.

Vídeo clases accesibles sobre el tema del agua como recurso didáctico-pedagógico para la promoción de la educación científica

Resumen. Los centros educativos tienen el reto de promover una gestión didáctico-pedagógica que promueva la inclusión de los estudiantes con discapacidad, que asegure el acceso equitativo a los contenidos curriculares. Este trabajo desarrolló una metodología de producción de videoclases accesibles sobre la temática del agua, utilizando experimentos como subsidio didáctico a los alumnos para contextualizar el proceso de producción de conocimiento científico. Se seleccionaron y se realizaron los experimentos afines al asunto con los estudiantes para comprobar las principales dudas sobre el conocimiento científico asociado y la manipulación de los materiales. Se generó un repositorio de videograbaciones con traducción a la lengua de signos. Profesionales especializados en la educación de personas sordas y profesores de ciencias hicieron una evaluación de la calidad didáctica y accesibilidad de estas videoclases ( $n=5$, con un total de 83 minutos de grabación). Teniendo en cuenta el aspecto divulgativo, se implementaron en estos vídeos, un código digital que, una vez activado, genera un cuestionario para comprobar el aprendizaje, además del guion para replicar los experimentos. Se concluye que este artículo puede contribuir a la promoción de la Educación Científica Inclusiva, considerando su metodología de producción centrada en los alumnos como protagonistas.

Palabras clave: enseñanza de la biología inclusiva; accesibilidad; educación para sordos.

Accessible video classes on the theme of water as a didactic-pedagogical resource for the promotion of scientific education

Abstract. Schools are challenged to promote didactic-pedagogical management that promotes the inclusion of students with disabilities, ensuring equal access to curriculum content. This work developed a methodology to produce accessible video classes on the water theme, we used experiments as a teaching aid to contextualize students with the process of producing scientific knowledge. The cognate experiments on the subject were selected and carried out with the students to verify the main doubts regarding the associated scientific knowledge and the manipulation of the materials. A video recording repository was generated with translation in Libras. These video classes $(n=5$, totaling 83 minutes of recording) were subjected to evaluation in relation to didactic quality and accessibility, by professionals specialized in teaching with deaf and science teachers. Considering the advertising aspect, a digital code was implemented in these videos, which, once triggered, generates a questionnaire to verify learning, in addition to the script for replicating the experiments. It is concluded that this article can corroborate for the promotion of Inclusive Scientific Education, considering its production methodology centered on students as protagonists, in addition to the video classes being resources for consultation with students, teachers and interpreters, also fulfilling a role of continuing education.

Keywords: Inclusive biology teaching; Accessibility; Deaf education. 


\section{Introdução}

O ensino das ciências deve fazer parte da formação de toda a sociedade. Podemos afirmar que, de acordo com o desenvolvimento econômico e educativo de cada país, o ensino de ciências é diferenciado em termos de valorização e eficácia (Bencze et al., 2013).

Mariani (2014, p.44) descreve a "Ciência como sendo aberta, incerta e relativa, tendo uma atividade dinâmica, provocando a compreensão humana, com um valor de caráter técnico, sendo a curiosidade a mola da sua existência".

Santos (2007) e Cunha (2017) compreendem a Educação Científica como uma agência institucionalizada prevalentemente nos espaços formais de ensino, referindose às escolas, que atua como uma espécie de interface de diálogo dos processos e produtos gerados pela comunidade de pesquisadores à sociedade.

Segundo Aragón (2016), há a necessidade de gerar uma proposta de arquitetura pedagógica comprometida não somente com a transposição didática destas informações altamente técnicas; mas deve-se objetivar a promoção de atitudes e valores colaboradores para que os estudantes consigam vincular os possíveis impactos éticos, econômicos, sociais e ambientais destes conhecimentos na sociedade em que estão contextualizados.

Tradicionalmente, a educação científica fundamenta-se numa concepção epistemológica em que o foco se atém na apreensão da lógica subjacente à consecução dos fenômenos e dos conceitos construídos, a partir de observações das relações causais. O apreço didático e devotado à aprendizagem (memorização) de fórmulas num contexto matematizante, conjugado à apropriação do capital léxico-semântico dos tópicos científicos apresentados, corroborando para um processo ensino-aprendizagem destituído de correlação com as vivências cotidianas. Isto, em última instância, não capacita o estudante a inter-relacionar os conhecimentos científicos adquiridos às demandas socioambientais, nem aos impactos das políticas públicas e privadas no âmbito científico-tecnológico.

Sobre o exposto, depreende-se que as instituições escolares contemporâneas devem comprometer-se com a formação de estudantes capazes de não somente tangenciariam os aspectos metodológicos científicos de compreensão dos fenômenos. Mas, elaborarem estratégias didáticos-pedagógicas capazes de contextualizar os conhecimentos científicos apreendidos à melhoria de qualidade de vida num nível individual e comunitário, e às consequências multidimensionais decorrentes da emergência e monopólio dos processos técnicos destes conhecimentos.

Nesta perspectiva, nomeada de letramento científico, o ensino de Ciências é comprometido com a cidadania uma vez que os conhecimentos ministrados convergem no empoderamento dos estudantes. Assim, capacita-os não somente a se apropriarem dos recursos tecnológicos em constante inovação, mas a (co) protagonizarem as transformações sociais por meio do desenvolvimento de senso crítico fundamentado, interferindo ativamente para implementação de um progresso sustentável (Cachapuz et al., 2005). 
Conjugado a esta demanda, as instituições regulares de ensino devem observar, no contexto de zelo pela equidade, um processo de educação científica que garanta a imersão dos alunos com deficiências ao processo de letramento científico (Villanueva et al., 2012). Neste contexto, verifica-se uma demanda premente no sentido de implementação de uma política educacional que conceba estratégias, objetivando a promoção de acessibilidade. O conhecimento científico, deve viabilizar aquisições de competências cognitivas que habilitem os educandos com deficiência a criticamente identificar a ocorrência dos fenômenos apreendidos em suas circunstâncias de vivências (Villanueva et al., 2012).

A despeito da Organização das nações Unidas para Educação e Ciência e Cultura (Unesco) (Unesco, 1994; Villanueva et al., 2012) estabelecer diretrizes, afirmando que a educação científica deve ser indistintamente garantida a todos. Sendo isto, um requisito fundamental para a efetivação da democracia, uma vez que, excedendo a exigência social, imputa desenvolvimento pleno do potencial intelecto humano. A análise de publicações nacionais demonstra intervenções isoladas num contexto de confrontação com as limitações impostas pelas deficiências, objetivando principalmente a socialização (Silva e Bego, 2018).

Em relação aos estudantes surdos, verifica-se que a principal intervenção para promoção da acessibilidade refere-se ao fornecimento de um profissional intérprete de Língua de Sinais para mediação da comunicação (Lima e Garcia, 2011).

Depreende-se disto que o método de inclusão adotado para os modelos antropomórficos citados, afigura-se em artifício superficial de adaptação que não promove disrupção com a didática fundamentada na epistemologia clássica da educação, principalmente pela reprodutibilidade da mecânica de transmissão de conhecimento no Atendimento Educacional Especializado (Da Silva et.al, 2020).

O que se verifica, portanto, é uma espécie de incipiência em termos de uma proatividade com respeito à geração de metodologias inovadoras e consistentes que atuem como modelo que possa ser reproduzido como ação de política pública educacional e capacitação continuada. Assim, preveniremos a ocorrência de sonegação de informações no processo educativo, por escusa da deficiência, propriamente (Zancan, 2000).

Em respeito aos educandos com impedimentos auditivos, foco desta pesquisa, a análise de diversos trabalhos demonstrou que, embora haja o reconhecimento de que a Língua Brasileira de Sinais (libras) seja a base para o aprendizado de qualquer conteúdo escolar, incluindo ciências e biologia, o processo de ensino-aprendizagem é comprometido por alguns fatores citados a seguir (Prince, 2011; Lima e Garcia, 2011):

a) Defasagens de muitos alunos no que concerne a conhecimentos prévios, devido à exposição tardia a Língua Brasileira de Sinais, verificando uma heterogeneidade em termos de necessidades educacionais no âmbito linguístico que abrange desde indivíduos analfabetos para Libras e língua portuguesa, até os indivíduos bilíngues;

b) Inexistência de sinais correspondentes aos termos biológicos, exigindo do intérprete recorrência às ilustrações em livros didáticos ou outro recurso pedagógico para facilitar a comunicação e apreensão do conteúdo; 
c) Comprometimento da interlocução entre o professor regente da disciplina e o intérprete por pouco domínio deste sobre o assunto, exigindo que ele apreenda o conteúdo antes do aluno;

d) "Alguns erros na interpretação de um tema específico, devido às falhas não intencionais nas traduções; a velocidade dos movimentos das mãos, a falta de imparcialidade, ou desconhecimento do conteúdo" (Mariani, 2014, p.47).

Dentre os impeditivos apresentados, reconhece-se que a criação e documentação de sinais para termos e conceitos específicos da biologia são vistas como possibilidades para a aprendizagem significativa de conteúdos da área das Ciências Biológicas (Prince, 2011; Lima e Garcia, 2011).

Finalmente, menciona-se que a integração destas ações colabora para a concepção de um projeto de educação científica e tecnológica inclusiva. Pois, além de preconizar a inserção dos estudantes no processo de produção de conhecimento científico por meio das experimentações, insere-os nas tecnologias digitais da informação e comunicação (TIDIC). As referidas videoaulas apresentam um código digital que, quando acionados, conduzem a uma espécie de estudo dirigido para certificação da aprendizagem, além de roteiros para reprodutibilidade dos experimentos por parte dos docentes.

\section{Metodologia}

Como critério de elegibilidade para a participação deste estudo, foram incluídos indivíduos com as características descritas a seguir:

a) Quanto aos profissionais intérpretes de Libras, para participação neste estudo, foram recrutados aqueles que apresentavam competência validada por certificado de cursos reconhecido pelo Ministério da Educação e Cultura ou pelo Programa Nacional para a Certificação de Proficiência no Uso e ensino da Língua Brasileira de sinais.

b) Quanto aos estudantes que participaram das aulas de realização dos experimentos, estes tiveram entre 11 e 18 anos, sendo regularmente matriculados no sexto ano do Ensino Fundamental nas instituições participantes, a saber, Colégio Pedro II (Campus Realengo II, Rio de Janeiro), para alunos videntes e ouvintes, e Escola Municipal Paulo Freire (Município de Niterói) para alunos surdos.

c) Quanto aos profissionais da educação que participaram da avaliação do produto gerado deste projeto por meio de preenchimento de questionário de pesquisa de opinião após a exibição das videoaulas, estes foram divididos em dois subgrupos, sendo o primeiro, professores de alunos regulares ouvintes e o segundo pedagogos ou docentes dominantes de libras que atuam diretamente com alunos surdos nas instituições especializadas ou regulares inclusivas.

Em respeito aos critérios de exclusão, estes são descritos a seguir: (1) Quanto ao intérprete profissional, aqueles que não conseguirem preencher o quesito de obrigatoriedade de certificação em Libras pelos recursos oficiais como especificado anteriormente; (2) Quanto aos estudantes, foram excluídos àqueles que (a) não eram alfabetizados em Libras (no caso de aluno surdo), (b) apresentassem deficiências de 
ordem intelectual, socioafetiva ou psiquiátrico (incluindo as relativas ao Transtorno do Espectro Autista e transtornos de humor), (c) apresentassem síndromes classificadas como cromossomopatias à semelhança da Síndrome de Down, Síndrome de Turner e Síndrome de Klinefelter, (d) fossem surdo-cegos; (e) não apresentassem a assinatura do Termo de Consentimento Livre e Esclarecido pelo responsável (caso de crianças e adolescentes) ou do próprio aluno (caso de indivíduos com idade igual ou superior a 18 anos), por fim, (3) profissionais da Educação que não tivessem regularmente atuando em instituições de ordem jurídica pública ou privada.

Quanto à população de estudantes partícipes deste estudo, essa é assim descrita: (a) Estudantes sem deficiência sensorial $(n=66)$, matriculados regularmente no sexto ano do Ensino Fundamental da Instituição Federal de ensino (Campus Realengo), com média de idade correspondente a 11 anos, sendo 34 (51,5\%) do sexo feminino e 32 (48,5\%) do sexo masculino. (b) Estudantes com deficiência auditiva ( $n$ = 7), regularmente matriculados na Escola Municipal Paulo Freire em Niterói, com média de idade de 13 anos, sendo, 1 (14,3\%) do sexo feminino e $6(85,7)$ do sexo masculino; (c) Estudantes com deficiência visual $(n=3)$ regularmente matriculados na Instituição Federal, com média de idade de 18 anos, sendo dois do sexo feminino $(66,7)$ e um do sexo masculino $(33,3)$.

Quanto aos profissionais referentes à educação que participaram da pesquisa, avaliando qualitativamente o produto, a saber, videoaulas legendadas e traduzidas em Libras sobre a temática água $(n=23)$, apresentaram uma idade média de 37 anos, sendo 7 do sexo masculino e 16 do sexo feminino. Destes, 10 (43\%) são profissionais que declaradamente trabalham como pesquisadores, docentes ou pedagogos com o público surdo.

Em todos os casos, incluindo, portanto, discentes, docentes e profissionais intérpretes, só participaram da pesquisa, posteriormente à assinatura do Termo de Consentimento Livre e Esclarecido. No caso do aluno menor legalmente, os responsáveis foram conscientizados da importância da pesquisa e das características éticas inerentes, como condição da coleta da assinatura do Termo de Consentimento Livre e Esclarecido. A pesquisa passou pelo comitê de ética e foi aprovado com o número do CAAE: 19633919.5.0000.9047 e o número do Parecer: 3.717.633.

\section{Seleção, testagem e adequação das atividades experimentais}

Posteriormente à pesquisa bibliográfica, foram selecionados experimentos no livro didático, contexto da temática água que corresponderam aos seguintes critérios de elegibilidade:

1. Pertinência ao nível de maturidade psicomotora dos estudantes alvos para que fossem executados de forma segura, sem riscos à integridade física deles, por ocasião de incentivos de realização dos experimentos de forma autônoma;

2. Exequibilidade no contexto do tempo respectivos às aulas;

3. Propiciassem um aprendizado significativo no contexto do processo científico como: reflexão, correlação dos fundamentos da metodologia com o objeto de investigação, análise crítica e diálogo entre os membros dos grupos constituídos, e inferências conclusivas sobre os resultados observados; 
4. Fossem cognitivamente significantes aos estudantes alvos deste estudo;

5. Fossem adequados à realidade estrutural de um ambiente de escola do ensino básico, refere ao espaço propriamente, à mobilização de recursos materiais e humanos;

6. Atendessem às expectativas bioéticas quanto suas diretrizes.

A execução do processo de seleção das práticas experimentais, segundo os critérios de elegibilidade mencionados, observou dois estágios, descritos a seguir: inicialmente, os experimentos selecionados foram reproduzidos no laboratório de Biologia da instituição, sendo avaliados os parâmetros de exequibilidade e biossegurança ${ }^{1}$, como descritos anteriormente. Prosseguindo, foram produzidos roteiros para o processamento dos experimentos, objetivando estabelecer orientações para participação autônoma dos estudantes. Tais roteiros foram constituídos de uma breve fundamentação teórica listagem dos materiais necessários e procedimento de execução do experimento, item para as observações vivenciadas com a execução da prática, item para exposição dos resultados esperados, referência bibliográfica e, finalmente, um questionário dirigido para fins de avaliação da aprendizagem.

A segunda instância do processo de avaliação e seleção dos experimentos deu-se na execução deles com estudantes ouvintes e surdos do sexto ano do Ensino Fundamental nas instituições participantes. Nesta etapa foram observados aspectos como: dificuldade de organização dos materiais e processamento experimental pelos estudantes, dificuldade de correlação entre os resultados observado e a apreensão dos conceitos subjacentes aos fenômenos estudados e a correlação entre o experimento e a motivação de sua execução pelos alunos.

Dadas as condições apresentadas, foram selecionados 12 experimentos que integraram o desenvolvimento das videoaulas num contexto de sequência didática, cuja arquitetura pedagógica consistiu na elaboração de cinco módulos interdependentes, em que a transmissibilidade do conhecimento se realizava por intermédio de uma breve exposição teórica, suplementada ou com modelos didáticos, ou com os experimentos mencionados.

Acaracterização da referida sequência didática, com descrição da identificação e dos objetivos dos experimentos ou modelos didáticos pertinentes aos respectivos módulos, encontra-se na Quadro 1.

As filmagens foram realizadas no laboratório de biologia, sendo o processo de edição executado por meio do Software Camtasia Studio 8.

No processo de edição das videogravações, foram inseridos códigos digitais de acionamento rápido por meio do aplicativo QR code Monkey (https://www. qrcode-monkey.com), com a finalidade de acesso a questionários para verificação de aprendizagem, além dos roteiros relativos aos experimentos para divulgação entre os docentes, cumprindo o papel de uma espécie de formação continuada.

\footnotetext{
${ }^{1}$ A biossegurança é o conjunto de ações voltadas para a prevenção, minimização ou eliminação de riscos inerentes às atividades de pesquisa, produção, ensino, desenvolvimento tecnológico e prestação de serviços, visando à saúde do homem, dos animais, a preservação do meio ambiente e a qualidade dos resultados (Teixeira \& Valle, 1996)
} 
Quadro 1. Relação dos experimentos selecionados para produção das videogravações com tradução em Libras

\begin{tabular}{|c|c|c|}
\hline $\begin{array}{c}\text { Título do } \\
\text { Experimento ou } \\
\text { demonstração } \\
\text { didática }\end{array}$ & Objetivos/Procedimentos & $\begin{array}{c}\text { Modelo didático ou Experimento } \\
\text { Executado }\end{array}$ \\
\hline \multicolumn{3}{|c|}{ Módulo 1: Caracterização estrutural e propriedades da água } \\
\hline $\begin{array}{l}1 \text { Caracterização } \\
\text { estrutural da mo- } \\
\text { lécula de água. }\end{array}$ & $\begin{array}{l}\text { Objetivo Principal: Demonstrar a carac- } \\
\text { terização estrutural da molécula de água } \\
\text { por meio de modelos didáticos, para } \\
\text { compreensão das propriedades físicas } \\
\text { e químicas, tais como, coesão, adesão, } \\
\text { capilaridade, tensão superficial, solvência } \\
\text { universal. } \\
\text { Objetivos Específicos: } \\
\text { - Construir modelos que demonstrem a } \\
\text { caracterização dos átomos, indicando } \\
\text { o núcleo e a eletrosfera e as partícu- } \\
\text { las presentes nestas regiões. } \\
\text { - Demonstrar, utilizando os modelos, } \\
\text { as relações de troca de elétrons no } \\
\text { contexto das ligações iônicas e co- } \\
\text { valentes. } \\
\text { - Explicar a constituição da molécula } \\
\text { de água, prevendo o compartilha- } \\
\text { mento desigual de elétrons. }\end{array}$ & $\begin{array}{l}\text { - Modelo didático relativo à consti- } \\
\text { tuição estrutural do átomo. } \\
\text { - Prancha com um modelo bidi- } \\
\text { mensional relativo aos átomos de } \\
\text { sódio e cloro. } \\
\text { - Prancha com um modelo bidi- } \\
\text { mensional relativo aos íons de } \\
\text { sódio e cloro. } \\
\text { - Modelo didático bidimensional, } \\
\text { relativo aos átomos de oxigênio } \\
\text { e hidrogênio em seus estados } \\
\text { fundamentais; } \\
\text { - Modelo didático bidimensional, } \\
\text { relativo ao processo de formação } \\
\text { da molécula de água, pós inte- } \\
\text { ração covalente entre os átomos } \\
\text { de hidrogênio e oxigênio. }\end{array}$ \\
\hline $\begin{array}{l}2 \text { Caracterização } \\
\text { das proprieda- } \\
\text { des da água, } \\
\text { resultantes da } \\
\text { sua constituição } \\
\text { estrutural quími- } \\
\text { ca }\end{array}$ & $\begin{array}{l}\text { Objetivo Principal: Demonstrar as prin- } \\
\text { cipais propriedades da água, correla- } \\
\text { cionando-as com aplicações cotidianas. } \\
\text { Objetivos Específicos: } \\
\text { - Explicar, utilizando modelos da estru- } \\
\text { tura molecular da água, a existência } \\
\text { de ligações intermoleculares resul- } \\
\text { tantes da geração de cargas elétricas } \\
\text { parciais, correlacionando com a } \\
\text { coesão. } \\
\text { - Explicar a propriedade de adesão. } \\
\text { - Explicar a propriedade de capilarida- } \\
\text { de por meio dos experimentos. } \\
\text { - Explicar a propriedade de solvente } \\
\text { Universal: }\end{array}$ & $\begin{array}{l}\text { - Modelo tridimensional relativo às } \\
\text { moléculas de água conectadas } \\
\text { intermolecularmente por meio de } \\
\text { pontes de hidrogênio. } \\
\text { - Demonstração de um processo } \\
\text { de capilaridade, utilizando um } \\
\text { papel toalha que atua como uma } \\
\text { espécie de ponte entre dois reci- } \\
\text { pientes para passagem de uma } \\
\text { solução aquosa colorida. } \\
\text { - Realização de misturas da água } \\
\text { com substâncias hidrofílicas e } \\
\text { hidrofóbicas. } \\
\text { - Condução de corrente elétrica } \\
\text { em soluções salinas, tendo como } \\
\text { elemento repórter, lâmpadas } \\
\text { acesas quando circuito entre } \\
\text { tomada-lâmpada-solução são } \\
\text { competentes. }\end{array}$ \\
\hline
\end{tabular}


Módulo 2: Estados Físicos da água e influência da temperatura na conversão dos estados físicos da água

3 Caracterização Objetivo Principal: Demonstraros estados dos estados físicos da água físicos da água e suas relações com o volume, forma e compressibilidade.

\section{Objetivos Específicos:}

- Apresentar a água nos três estados físicos, demonstrando experimentalmente, a relação destes estados de agregação com a forma, volume e nível de compressibilidade.

- Relacionar ainda as forças de coesão e repulsão das moléculas nestes três estados.

\section{Mudança de} estados físicos da água e correlação com o ciclo da água na Natureza
Objetivo Principal: Caracterizar os processos de alteração dos estados físicos da água sob a influência da temperatura, relacionando com o ciclo hidrológico na Natureza.

\section{Objetivos Específicos:}

- Demonstrar por meio de experimentação, a Inter conversão dos estados físicos da água, criando um sistema de simulação.

- Provando a existência do vapor de água no ar por meio de experimentação.
- Apresentação da água no estado sólido, líquido e gasoso (vapor).

- Influência da temperatura na conversão dos estados físicos da água, por meio da submissão de gelos a uma fonte de energia térmica.

- Alteração do ponto de solidificação da água, por meio de adição de sal em gelo.

- Demonstrando o processo de condensação do vapor de água no ar, expondo-o a uma superfície de garrafa plástica com gelo em seu interior.

Módulo 3: Estudo introdutório das forças que atuam em objetos imersos em água

5 Densidade

\section{Princípio de Arquimedes (Empuxo)}

Objetivo Principal: Consolidar conceitos sobre densidade através de observação experimental relacionando sua aplicabilidade em atividades humanas e em fenômenos da natureza.

Objetivo Específico:

- Demonstrar por meio de sistemas experimentais a propriedade de densidade

Objetivo Principal: Definir empuxo, explicando por que objetos ficam aparentemente mais leves quando mergulhados em água em relação ao meio externo à água.

Objetivo Específico:

- Construir um sistema experimental que demonstre a existência do empuxo, correlacionando sua importância com a flutuabilidade dos objetos presentes em corpos hídricos.
- Demonstração de modelo didático

- Prancha didática relacionada à densidade

- Procedimentos experimentais:

- Submersão de dois objetos de mesmo volume com quantidades de massas diferentes na água.

- Flutuabilidade do ovo cru em água "pura" e água misturada com sal de cozinha.

- Geração de uma torre líquida.

- Verificação do comportamento de objetos de massas conhecidas quanto à força peso real e aparente em situações em que estes objetos estão imersos e fora d'água, respectivamente. 
As filmagens foram realizadas no laboratório de biologia, sendo o processo de edição executado por meio do Software Camtasia Studio 8.

No processo de edição das videogravações, foram inseridos códigos digitais de acionamento rápido por meio do aplicativo QR code Monkey (https://www. grcode-monkey.com), com a finalidade de acesso a questionários para verificação de aprendizagem, além dos roteiros relativos aos experimentos para divulgação entre os docentes, cumprindo o papel de uma espécie de formação continuada.

Quanto à inserção de legendas, esta foi realizada por meio de transcrição prévia dos vídeos com a mediação de um programa presente no YouTube Studio (https://studio.youtube.com).

Em relação à gravação do processo de interpretação em Libras, este se realizou assincronicamente à produção das gravações dos experimentos, ou seja, após a edição das filmagens, incluindo a legendagem. A edição adicional para a inserção da janela de tradução no vídeo foi feita observando as diretrizes da ABNT 15290.

Dado a existência de termos técnicos-científicos, foi produzido um glossário, consultando repositórios nos seguintes sítios eletrônicos, INES (molécula em libras SinQui / INES - Sinalário ilustrado de química em libras, https://bit.ly/3wQ5wbY); IFSC Palhoça Bilíngue (https://bit.ly/3kvwMKl) e Spread The Sign, (https://bit.ly/2UVyKcj).

Prosseguindo, em relação ao método de avaliação das videoaulas produzidas, considerou-se a participação de docentes das disciplinas de ciências e biologia, além de pedagogos e/ou docentes que trabalham diretamente com alunos surdos. $A$ estratégia para recrutamento dos referidos docentes consistiu em convite virtual para acesso aos links das videoaulas e, subsequentemente preenchimento do questionário correspondente à pesquisa de opinião, produzido pela ferramenta Formulário do site Google (https://bit.ly/3ezyvKZ ), sendo esta estratégia adotada em virtude do contexto pandêmico.

Quanto à avaliação qualitativa, foram feitos gráficos do tipo Radar e análise de frequência relativa sobre os dados gerados da aplicação da escala Likert. Mencionase que os docentes participantes desta investigação deveriam estar matriculados regularmente em instituições públicas ou privadas de ensino.

A construção da referida página no canal do Youtube apresenta recursos de comunicação assíncrona com a finalidade de analisar as sugestões e críticas dos usuários, gerando um recurso para a promoção do aperfeiçoamento no processo de produção de filmagem.

\section{Resultados}

Este projeto foi desenvolvido por meio de uma cooperação interinstitucional, envolvendo uma Instituição Federal de Ensino, a saber, Colégio Pedro II (Rio de Janeiro) e uma Escola Municipal com foco em Inclusão pertencente à Cidade de Niterói (Escola Municipal Paulo Freire).

Entendendo a importância da comunicação em Libras para efetivação cognitiva dos educandos com perda auditiva, inicialmente à produção das videoaulas, realizouse uma pesquisa em repositórios com caráter de glossários para a recuperação de sinais instituídos relativos a termos científicos associados à água. 
No processo de busca, prontamente detectou-se escassez de produções documentadas e publicitadas em sítios eletrônicos institucionais de credibilidade, uma vez que não se garantia premissas como (a) emergência do sinal a partir do surdo, respeitando a cultura surda, ou (b) referências de universalização destes referentes como sinal linguístico em níveis territoriais abrangentes, incluindo os níveis regionais brasileiros ou de caráter nacional.

Desta investigação, foram elencados 18 sinais a partir dos quais realizamos a gravação, baseando-se, portanto, em sinais já existentes e reconhecidos pela comunidade para servir como glossário de apoio aos discentes durante a realização das atividades. $\mathrm{Na}$ figura 1 podemos visualizar fotoregistros obtidos dos vídeos produzidos.

O presente glossário contém os seguintes termos: átomo, ânion, camadas eletrônicas, elemento químico, elétron, íons, líquido, mistura heterogênea, mistura homogênea, molécula, nêutron, núcleo, próton, solidificação, sólido, sublimação, substância, vaporização. Este glossário foi postado no site do Educapes: https://bit. ly/3BgWyb7, https://bit.ly/3BjQ6QJ, https://bit.ly/3zdz5FR, https://bit.ly/3rlnTUT, https:// bit.ly/2V1VAnq.

Figura 1. Glossário contendo os termos ânion, átomo, elétron, íon, solidificação e vaporização.
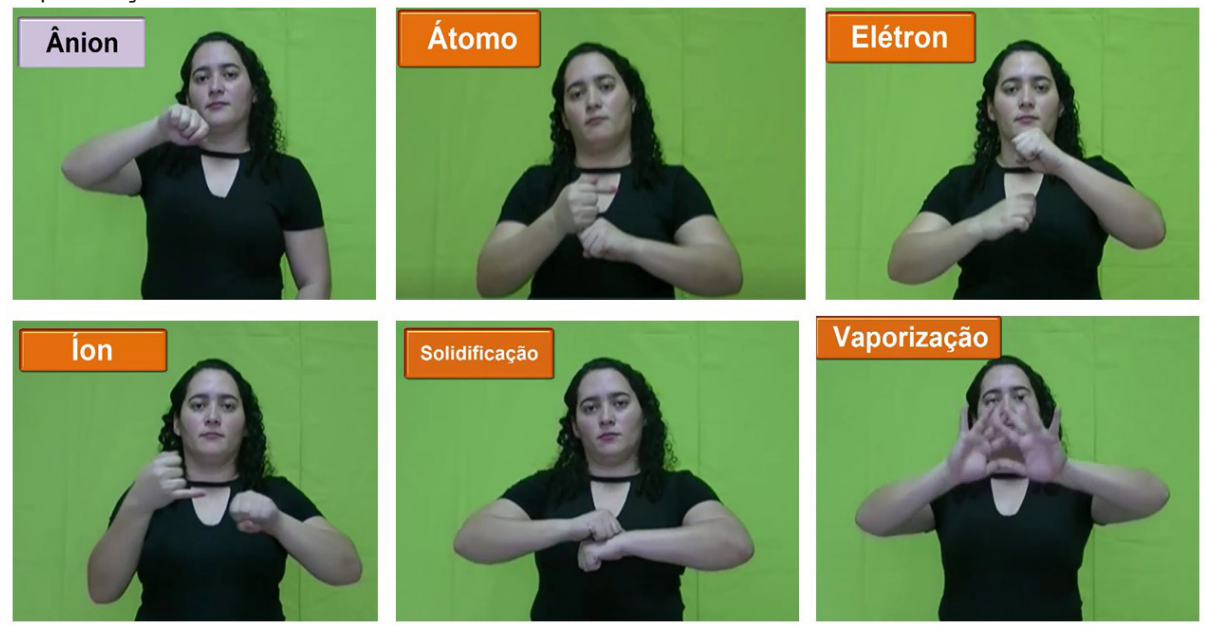

Fonte: Arquivo pessoal

As filmagens foram realizadas no laboratório de Biologia do colégio sendo empregados recursos adquiridos de verbas de fomento à pesquisa, provenientes da Fundação de Amparo à Pesquisa do Estado do Rio de Janeiro e da Pró-reitora de Pós-Graduação, Pesquisa, Extensão e Cultura do Colégio Pedro II. descritas:

A produção de videoaulas subdividiu-se em três etapas que podem ser assim

1. Reprodução experimental em laboratório próprio, objetivando testar a viabilidade da execução dos experimentos selecionados, considerando parâmetros como exequibilidade e biossegurança, além da definição de ângulos de enquadramento que demonstrassem a ocorrência dos fenômenos gerados 
na experimentação ou demonstração dos modelos didáticos, tendo em vista o registro destas observações na composição dos roteiros para filmagem;

2. Aplicação das práticas experimentais e promoção da interação dos discentes surdos e ouvintes com os modelos produzidos (Figuras 2 e 3). Visando o aumento da eficácia por ocasião da ministração das videoaulas, considerando as previsibilidades em termos de espectro de dificuldades observados na ministração das oficinas experimentais e demonstração dos modelos aos educandos surdos e ouvintes, nesta etapa objetivou-se o aperfeiçoamento dos recursos didáticos produzidos quanto às suas insuficiências no processo de transmissibilidade do conhecimento; reconhecimento e registro das dificuldades surgidas no processo de comunicabilidade, executando levantamento das dificuldades de comunicação em libras e prevendo o estabelecimento de descritores na ausência de sinais de termos técnicos; formação de uma espécie de inventário em relação às dificuldades inerente à compreensão dos conceitos e fenômenos subjacentes à temática água.

3. Filmagem, edição e legendagem, considerando parâmetros qualitativos como perspectivação, tempo, atendimento das necessidades dos alunos ouvintes e surdos alvos do estudo.

Figura 2. Aplicação dos experimentos com os alunos do Colégio Pedro II.
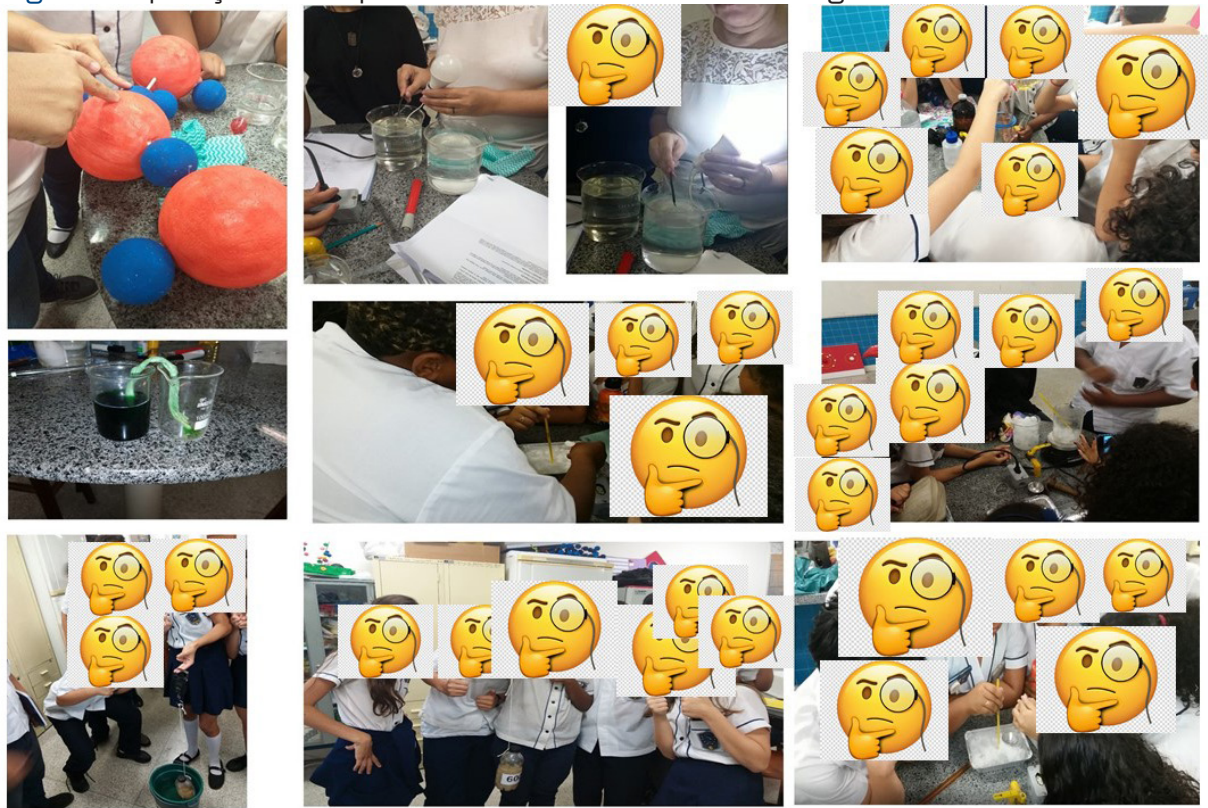

Fonte: Arquivo pessoal

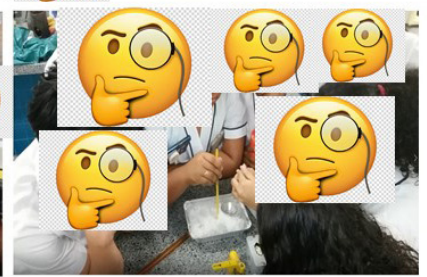


Figura 3. Aplicação dos experimentos no laboratório com alunos da rede municipal de Niterói
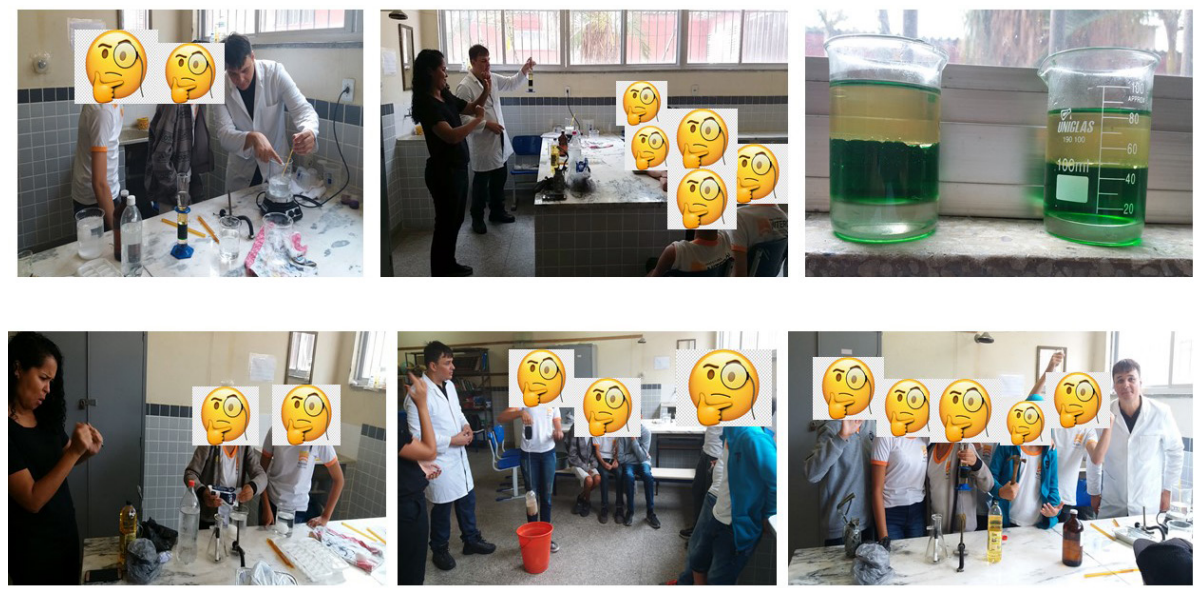

Fonte: Arquivo pessoal.

Prosseguindo, para a produção dos vídeos propriamente, foram considerados como diretrizes, parâmetros correspondentes à (1) observação do bilinguismo, uma vez que fornece um processo de explicação em Libras e uma audiodescrição em língua portuguesa, consubstanciada pela legenda, (2) além de contextualizar o processo pedagógico com os pressupostos da didática imagética, recorrendo a recursos como modelos e experimentos como suplementos para efetivação da comunicação dos conhecimentos científicos.

Secundariamente, o processo de produção das videoaulas não se eximiu dos pressupostos da metodologia científica, estabelecendo, por exemplo, sistemas controle para contrastes dos resultados e emergência do conhecimento científico pela observação. Ao todo, foram produzidas cinco videoaulas, totalizando 83 minutos de comunicação científica sobre a temática água (Figura 4).

Figura 4. Fotoregistro dos vídeos produzidos.
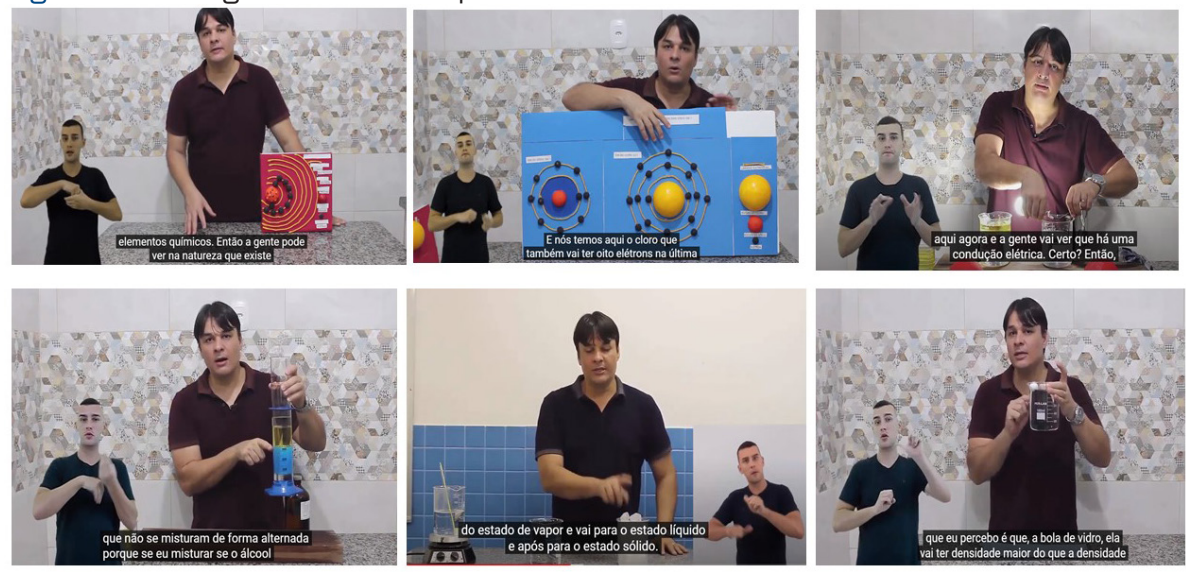

Fonte: Arquivo pessoal. 
Os vídeos produzidos foram depositados em um sítio eletrônico de domínio público, disponibilizando-os, prontamente, como recursos a consultas de docentes, intérpretes, estudantes ouvintes e surdos, concretizando um objetivo de divulgação científica, dos conhecimentos abordados (Tabela 1).

Tabela 1. Endereços eletrônicos correspondentes às videoaulas com tradução em Libras

Videoaula 1 - Água - Introdução (Importância e Caracterização Molecular) https://bit.ly/3zcT87p Parte I

Videoaula 2 - Água - Introdução (Importância e Caracterização Molecular) https://bit.ly/2UUBPJt Parte II

Videoaula 3 - Comportamento das Substâncias em Meio Aquoso: AÁgua https://bit.ly/3riScfo Como Solvente Universal.

Videoaula 4 - Estados Físicos da Água e Conversões https://bit.ly/3x0xNNf

Videoaula 5 - Estudo da Densidade e sua Influência sobre Objetos Imersos https://bit.ly/3kvEUKV em um Líquido -

Fonte: Arquivo pessoal.

O processo de investigação quanto à opinião sobre a qualidade das videoaulas efetivou-se com a participação de 23 profissionais da educação, que responderam um questionário para este fim dentre os quais, $40 \%(n=10)$ confirmam serem profissionais que atuam diretamente com o público surdo. Quanto à estratificação profissional, aproximadamente $72 \%(n=16)$ atuam como docentes na área de biociências, enquanto $24 \%(n=5)$ são pedagogos e $4 \%(n=1)$ atuam no campo psicológico com enfoque em inclusão.

Sobre a sondagem de suas atuações no campo da Educação Científica, aproximadamente $68 \%(n=16)$ dos profissionais relataram trabalharem em instituições que apresentam laboratórios, sendo que destes, apenas $41 \%(n=7)$ afirmam que os laboratórios têm equipamentos, incluindo vidrarias, reagentes, para realizarem suas atividades práticas. Dos 17 docentes, cujas instituições apresentam laboratórios, apenas 7 (44\%) realizam práticas experimentais.

Esses resultados são concordantes com a literatura no que concerne à realidade das escolas públicas em que inexistem um espaço próprio destinado a práticas experimentais ou são subutilizados por falta de recursos e condições de biossegurança (Teixeira e Valle, 1996).

Adespeito da proposição de atividades de práticas experimentais frequentemente significar apenas um procedimento mecânico de reprodução das etapas prescritas em um roteiro inflexível, isso não representar garantia de apreensão significativa dos conteúdos. Menciona-se que, numa ambição pedagógica mais modesta, torna-se fundamental à viabilidade de uma constatação empírica dos fenômenos caracterizados de forma expositiva. Isso colabora para um processo de apreensão dos conteúdos que não dependa exclusivamente da abstração (Alves, 2016).

Em última instância, o processo de educação científica é comprometido no seu aspecto de inserção dos educandos ao método de produção de conhecimento científico. Verificando a limitação das aulas de ciências a argumentações problematizadoras 
ou à compreensão das inter-relações das variáveis concernentes a um fenômeno de forma algébrica, não escapando as duas intervenções da dependência do exercício da abstração (Santos, 2007).

Prosseguindo, no contexto analítico das opiniões sobre as videoaulas produzidas em libras com foco em demonstrações de modelos e experimentos como subsídio para suplementar à comunicabilidade dos conteúdos (observando os pressupostos da pedagogia visual, bilinguismo e educação científica), em síntese pôde-se observar ótima aceitação do recurso produzido como proposta metodológica de ensino que atende ao público surdo e ouvinte.

O processo de avaliação subdividiu-se, considerando dois grandes grupos profissionais: (a) aqueles que especificamente atuam na educação do surdo; e (b) aqueles que atuam como docentes de biociências, incluindo, química, física e biologia (ciências no ensino fundamental). Assim, no contexto das questões comuns, pode-se verificar que:

Quanto à estética, incluindo parâmetros como tempo e qualidade em termos de aspecto visual, 12\% (Figura 5) dos participantes atribuíram uma opinião negativa, verificando principalmente, tratar-se do grupo que trabalha com surdos. Em suas justificativas, percebe-se que as opiniões estão condicionadas à falta de um contraste entre o fundo e alguns fenômenos demonstrados nos experimentos ou ainda, quanto à janela do intérprete, sugerindo modificações neste sentido, conforme expresso a seguir:

"Os vídeos são excelentes e de alta qualidade. Para melhorá-los ainda mais tenho duas sugestões a fazer: 1) quando você mostra as representações, poderia ampliá-las por uns 10 segundos, por exemplo, para quem assiste poder ler e visualizar melhor o que está escrito nelas (por exemplo, as das ligações químicas e a da densidade tive dificuldade para ler, mas com sua explicação dá para entender)" (Participante 19).

"O intérprete estava sem fundo diferenciado (...) causando confusão visual" (Participante 20).

"O professor que fala deve parar de falar ao demonstrar qualquer ação e/ou imagem, para que o surdo possa também parar de olhar o intérprete e observar a ação e/ou imagem. Isso foi o que mais me incomodou nos vídeos. A falta de pausas nas falas para o surdo se concentrar na ação, na demonstração" (Participante 21).

Em relação ao tempo, igualmente 12\% (Figura 5) declararam não ser adequado ao telespectador, atribuindo ao declínio da capacidade de manutenção da atenção. Assim, concluiu-se que tais opiniões são proposições positivas para ajustamento técnico sobre o aumento da eficácia dos vídeos em sua proposta, pois todos concordaram de se tratar de um recurso didático relevante para o surdo.

"Tenho dado muitos vídeos aulas durante esse período de isolamento, e percebi que aulas curtas, de 10 minutos, facilitam no processo de entendimento. Então minha sugestão seria para o total de tempo das aulas" (Participante 11).

Quanto à proposta didático-pedagógica (abrangendo os quesitos considerações sobre as explicações, vinculação da transmissão de conhecimento com demonstrações de modelos e experimentações e inferência sobre a aprendizagem 
do aluno a partir das videoaulas), a média dos participantes que opinaram positivamente foi de $91 \%$ contra $4 \%$ dos que opinaram negativamente e 5 dos que foram indiferentes (Figura 5).

Novamente, verificou-se aqui atenção para estratégia específica quanto ao ensino para o surdo: os comentários justificadores das opiniões indiferentes ou negativas consistiram em solicitação de pausa no processo de exposição quando se tratar de demonstrações de estruturas e fenômenos para que haja sincronia entre a atenção devotada à comunicação visual gestual, própria da libras, inerente à atuação do intérprete e a visualização do referente como expressado.

Cita-se ainda, que no processo de avaliação das aulas especificamente há um relato recorrente de que a menos apreciada correspondeu às primeiras relativas à explicação sobre a caracterização estrutural da molécula de água. Interessante que quando a análise é conjugada a justificativa, identifica-se que o critério de não identificação com a videoaula trata-se do fato de não haver experimentos ou ser expositiva, como se segue:

"Estrutura molecular. Ele é o conteúdo mais fechado e técnico" (Participante 2). "As aulas que menos gostei foram as que não envolveram experimentos que incitam a curiosidade do aluno" (Entrevistada 14).

Entretanto, verifica-se a não compreensão de que o conteúdo é que restringe a abordagem por se tratar de caracterização de estrutura microscópica.

Quanto à importância das videoaulas, todos os partícipes concordaram ser um recurso pedagógico apropriado para o educando surdo.

"Todas são interessantes e didáticas" (Entrevistada 8).

"Eu gostei de todas as videoaulas, as explicações foram pertinentes e quando trabalhamos com material concreto há um interesse maior por parte dos alunos" (Participante 6).

Foi questionado aos profissionais relacionados diretamente com os surdos, sobre o fato das videoaulas estarem apropriadas quanto aos pressupostos da pedagogia visual e bilinguismo, ressalvando a necessidade de ajustes da fala por ocasião da manifestação dos fenômenos e demonstrações estruturais, todos concordaram que o projeto está contextualizado com a proposta pedagógica em questão. A presença do intérprete e legenda opcional é importante para a proposta de transmissão de conhecimento ao estudante surdo.

\section{Discussão e conclusão}

As instituições regulares de ensino contemporâneas estão circunstanciadas sob o paradigma da inclusão, requerendo o desenvolvimento de políticas pedagógicas que ultrapassam a meta da simples inserção/socialização do educando com necessidades educacionais específicas, decorrentes de deficiências sensório-intelecto-motor, isoladas ou combinadas. Há uma demanda premente de garantir o desenvolvimento cognitivo de tais estudantes sob uma perspectiva de geração de estratégias didáticopedagógicas que lhes assegurem acesso em condições igualitárias aos conteúdos curriculares como instituídos nos programas estabelecidos, evitando que informações sejam sonegadas escusas da deficiência, propriamente. 
Neste contexto, a efetivação do processo de inclusão não pode prescindir de um atendimento especializado em que seja oportunizado uma inter-relação direta com o educando, uma vez que neste processo há a viabilidade de se reconhecer o capital de conhecimento prévio do aluno em questão, as restrições cognitivas decorrentes da deficiência e a concepção de intervenções com aporte de metodologias e recursos que conduzam aprendizagem num contexto de constante vigilância da eficácia destas estratégias, considerando a heterogeneidade interindividual em termos de necessidades educativas num mesmo modelo de deficiência.

Conjugado à demanda supracitada, há uma urgência de promover educação científica num contexto de letramento, perspectivando não somente à capacitação dos estudantes ao domínio dos recursos científicos-tecnológicos, mas a formação de um estudante capaz de problematizar os avanços científicos quanto a questões éticas e de impacto socioambiental, possibilitando a emergência de uma ciência cidadã em que os conhecimentos emponderem os educandos a coprotagonizarem as transformações decorrentes da pretensa implementação destes saberes quanto suas consequência multidimensionais na sociedadec

Sob estas demandas, o desenvolvimento deste projeto fundamentou-se nos seguintes parâmetros:

a) Desenvolvimento de recursos didáticos centrados nas necessidades educativas do usuário (design com foco no usuário) - Previamente à produção das videoaulas, os modelos didáticos e os experimentos selecionados foram submetidos à interação com os alunos ouvintes e surdos, possibilitando elencar um repertório de dificuldades ao público deste estudo, o que resultou na formação de um repertório de previsibilidades em termos de impedimentos cognitivos que puderam ser tratados por ocasião da execução das videogravações. Além disso, as videoaulas foram concebidas, observando os princípios do bilinguismo e da pedagogia visual, como abordados anteriormente.

b) Introdução dos alunos surdos e ouvintes no laboratório - Existe toda uma vivência laboratorial que é sonegada aos estudantes, referindo-se ao contato com artefatos e equipamentos que são importantes para as definições de parâmetros quantitativo e qualitativo das experimentações. Isto exige posturas padrões para a execução do que se chamam boas práticas de laboratório, com objetivo de prevenir erros nos resultados condicionados à má utilização dos instrumentos de medida, de reservatório ou de transferência. Portanto, introduzir o estudante no laboratório é oportunizá-lo a vivência de profissionais cientistas, fazendo-Ihe reconhecer que o processo empirista de investigação se realiza sobre um contexto de máxima prevenção quanto a interferências de erros próprios da execução. Exigindo assim, que haja reprodutibilidade para validação dos resultados, tanto em nível dos controles instituídos pelos autores da pesquisa, quanto por intergrupos.

c) Introdução dos educandos surdos e ouvintes num processo de produção de conhecimento científico no contexto empírico-racionalista A arquitetura experimental possibilita a imersão do estudante na proposta metodológica de produção de conhecimento circunstanciada pela epistemologia empíricoracionalista. A organização em grupos viabiliza a ocorrência de comunicação (mediada em libras no caso dos estudantes surdos), viabilizando cooperação 
em um nível intersubjetivo para a emergência do conhecimento, caracterizando um processo ontogênico de cognição ${ }^{2}$, fundamentado em discussões racionalizadas a respeito das observações verificadas nas reações experimentais.

d) Inclusão nas tecnologias digitais de comunicação e informação - A disponibilização das videoaulas em um sítio de domino público com possiblidade de discussão por meio de um canal de comunicação, à semelhança dos fóruns virtuais, cumpre uma finalidade de inclusão tecnológica dos estudantes surdos e ouvintes. Análise dos comentários dos mais variados públicos, possibilitará uma espécie de formação de comunidade socializadora do conhecimento, tendo em vista a integração de uma heterogeneidade de perspectivações sobre o tema, concordantes com as vivências de cada indivíduo. Além disso, a aprendizagem pode ser alcançada por ocasião de intervenções dos autores das postagens, caso seja verificado considerações equivocadas ou insuficientes. Essas ações possibilita um endossamento de uma cultura no contexto das Tecnologias digitais da informação e comunicação (TIDIC) tão cara ao processo de educação à distância como sustentado atualmente.

Prosseguindo, constata-se que a implementação de um processo de educação científica no contexto da pessoa com impedimento auditivo deve suplantar obstáculos antecipadamente inerentes à aprendizagem e à influência da língua de sinais (libras), reconhecendo-a como principal mediador do empoderamento do estudante surdo como partícipe em termos de acesso e apropriação dos bens sociais, em sociedades essencialmente científico-tecnológicas (Alves et al., 2010; Paiva e Bendassolli, 2017). Esclarecemos que o grupo discente surdo é heterogêneo quanto ao domínio de Libras ou língua portuguesa, apresentando um espectro que nas extremidades encontramse desde os não alfabetizados em alguma língua até aqueles totalmente bilíngues.

Especificamente às videoaulas produzidas, no contexto da comunicação, todos os partícipes concordam que a presença do intérprete, associada com a legenda (sendo esta opcional) é concordante com os pressupostos do bilinguismo no processo educacional do surdo. Além disso, a recorrência de elementos imagéticos com os modelos e os experimentos como subsidiadores suplementares das informações, são adequados, respeitando a pedagogia visual.

Sob a importância das videoaulas legendadas e traduzidas em Libras destacamse: (1) atuam como material de consulta para fins de aprendizagem e revisão; (2) atuam como um material de apoio, contribuindo para formação continuada a docentes, dado o fornecimento dos roteiros e a visualização da demonstração prática; (3) antecipa ao intérprete de Libras, informações técnicas sobre o assunto para revisarem e refletirem sobre um repositório de previsibilidade das possíveis dificuldades geradas no exercício de sua atividade em uma aula real.

Finalmente, incluir o estudante com perda auditiva (e o ouvinte) na educação científica garante-lhe o direito de vivenciar os atributos do processo de produção do conhecimento, fomentando percepções que podem gerar perspectivações quanto

\footnotetext{
${ }^{2}$ A ontogênese cognitiva num contexto epistemológico sócio-histórico-cultural resulta das diversas instâncias de inter-relações a que um indivíduo se contextualiza no processo de seu desenvolvimento. Admite que a importância do desenvolvimento filogenético se refere ao fornecimento do substrato biológico e pondera que a emergência da aprendizagem decorre das mediações realizadas por meio da comunicação, especialmente a linguística.
} 
ao despertamento de uma vocação para áreas científicas, além de corroborar para apreensão significativa dos conteúdos por verificação real num contexto "hands on" 3 em que o estudante pode protagonizar as vivências que resultam em aprendizagem.

\section{Referências}

Alves, C. B., Ferreira, J. de P. \& Damázio, M. M. (2010). A Educação Especial na Perspectiva da Inclusão Escolar Abordagem Bilíngue na Escolarização de Pessoas com Surdez. Brasília: Ministério da Educação/Universidade Federal do Ceará. Disponível em https://bit.ly/2TplAmi

Alves, S.M. (2016). Desenvolvimento humano, cognição e educação: reflexões sob o enfoque históricocultural. Revista Reflexão eAção, 24(2), 197-214. http://dx.doi.org/10.17058/rea.v24i2.4617

Aragón, R. (2016). Interação e mediação no contexto das arquiteturas pedagógicas para a aprendizagem em rede. Revista de educação pública, 25(59), 261-275. Disponível em https://www.lume. ufrgs.br/handle/10183/150441

Bencze, J. L., Lyn, C., Mei-Hung, C., Reinders, D., Sonya, M.; Christina, S.; Joseph, K. R.; Namsoo, S.; Kyunghee, C.; Hyunju, L.; Sung-Won, K. (2013). Globalization And Science Education. Cosmos, 8(2), 139-152. https://doi.org/10.1142/S021960771250005X

Cachapuz, A. C., Pérez, D. G. P., Carvalho, A. M. \& Praia, J. (2005). A necessária renovação do ensino das ciências. São Paulo: Cortez. Disponível em: https://bityli.com/cMx9D .

Cunha, R. B. (2017). Alfabetização científica ou letramento científico? interesses envolvidos nas interpretações da noção de scientific literacy. Revista Brasileira de Educação, 22(68). http://dx.doi.org/10.1590/s1413-24782017226809.

Da Silva, R.I., Xavier, A.L.C., dos Santos, A. L. T. L. \& Braz, R. M. M. (2020). Desenvolvimento de sequência didática sobre o tema membrana plasmática como recurso didático-metodológico para promoção de aprendizagem de alunos cegos: Introdução. Vivências, 16(31), 269287. https://doi.org/10.31512/vivencias.v16i31.255.

Lima D. B. de \& Garcia R. N. (2011). Uma investigação sobre a importância das aulas práticas de Biologia no Ensino Médio. Cadernos do Aplicação, 24(1). https://doi.org/10.22456/25954377.22262.

Mariani, R. (2014). Libras - A construção e a divulgação dos conceitos científicos sobre o ensino de ciências e biotecnologia: integração internacional de um dicionário científico online; Tese de doutorado do curso de Ciências e Biotecnologia. Universidade Federal Fluminense. Niterói, pp.1-136. Disponível em https://bit.ly/3exIPmo

Mota, A. R. \& Rosa, C. T. W. da (2018). Ensaio sobre metodologias ativas: reflexões e propostas. Revista Espaço Pedagógico, 25( 2), 261-276. https://doi.org/10.5335/rep.v25i2.8161.

Paiva, J. C. M. \& Bendassolli, P. (2017). Políticas sociais de inclusão social para pessoas com deficiência. Psicologia em Revista, 23(1), 418-429. http://dx.doi.org/10.5752/P.16789563.2017v23n1p418-429

Prince, M. (2011). Ensino de Biologia para Surdos: Conquistas e desafios da atualidade. Trabalho de Conclusão de Curso de Licenciatura em Ciências Biológicas. Universidade Presbiteriana Mackenzie. São Paulo. Disponível em: https://gg.gg/upc.5o .

\footnotetext{
${ }^{3}$ O termo "hands on" refere-se a uma proposta didática no contexto do ensino de ciências, fundamentada na execução de experimentos. Intenta-se contextualizar os alunos com as práticas experimentais, fornecendo-lhes roteiros nos âmbitos inflexíveis (com etapas pré-estabelecidas, incluindo o resultado esperado) ou abertos (não mencionando os resultados, expectando que os discentes elaborem suas discussões e conclusões). O objetivo destas metodologias refere-se à promoção cognitiva por meio da operacionalização e o empirismo, exigindo que os educandos coloquem "mão na massa" (Mota e Rosa, 2018)
} 
Santos, W. L. P. (2007). Educação científica na perspectiva de letramento como prática social: funções, princípios e desafios. Revista brasileira de Educação, 12(36), 474-492. https:// doi.org/10.1590/S141324782007000300007.

Silva, L. V. \& Bego, A. M. (2018). Levantamento Bibliográfico sobre educação especial e ensino de ciências no Brasil. Rev. Bras. Ed. Esp., 24(3), 343-358. https://doi.org/10.1590/S141365382418000300003

Villanueva, M., Taylor, J., Therrien, W. \& Hand, B. (2012). Science education for students with special needs. Studies in Science Education, 48. 187-215. https://doi.org/10.1080/14703297.2 012.737117

Teixeira, P. \& Valle, S. (1996). Biossegurança. Uma abordagem multidisciplinar. FIOCRUZ, Rio de Janeiro. Disponível em: https://bit.ly/3hl44nQ.

UNESCO (1994). The Salamanca statement and framework for action on special needs education. Paris: United Nations Educational, Scientific and Cultural Organization (UNESCO). Disponível em https://bit.ly/3kDvIEa

Zancan, G.T. (2000). Educação científica uma prioridade nacional. Perspectiva, 14(1). https://doi. org/10.1590/S010288392000000300002

Cómo citar em APA:

Da Silva, R., Goudinho, L., Ribeiro, A., Vasconcelos, J., Pinto, S. \& Braz, R. M. (2021). Videoaulas acessíveis sobre a temática água como recurso didático-pedagógico para promoção da educação científica. Revista Ibero-americana de Educação, 87(1), 95-113. https://doi.org/10.35362/ rie8714528 